\section{Is it time to change the approach to oxygen therapy in the breathless patient?}

\section{Richard Beasley, Sarah Aldington, Geoffrey Robinson}

\section{The need to highlight the risks of high flow oxygen in clinical teaching}

l $\mathrm{n}$ a recent commentary we argued that the traditional representation of the haemoglobin oxygen dissociation curve developed by physiologists may be disconcerting for clinicians because of the prominence of the steep slope of oxygen desaturation with falling oxygen tension. ${ }^{1}$ We proposed that a different alignment may be preferable for clinicians in demonstrating its beneficial characteristics, enhancing both the "pick up" of oxygen despite cardiorespiratory disease and the "drop off" of oxygen to the tissues despite falling oxygen saturation (fig 1). It was hoped that, through a different perspective of the haemoglobin oxygen dissociation curve, it might be possible to overcome the ingrained practice of doctors, nurses and paramedics to prescribe high flow oxygen to breathless patients who do not necessarily have arterial hypoxaemia. ${ }^{2-4}$ However, such a change of long established practice would also require a recognition of the risks of inappropriate high flow oxygen therapy. ${ }^{5} 6$

The potential adverse pulmonary effects of high flow oxygen therapy were recognised soon after its widespread use in clinical practice. High flow oxygen was
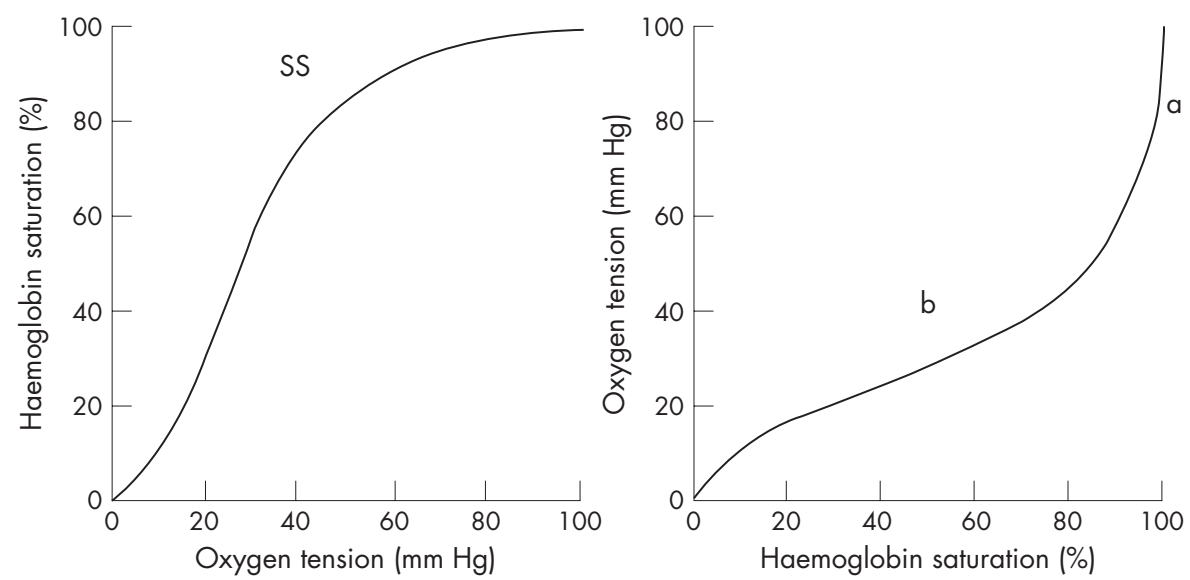

Figure 1 Left: Traditional representation of the oxyhaemoglobin dissociation curve with the "slippery slope" (SS). Right: Oxyhaemoglobin dissociation curve realigned to demonstrate its two key

characteristics: (a) haemoglobin maintains high levels of saturation despite marked reductions in oxygen tension, and (b) oxygen tension remains relatively stable as oxyhaemoglobin saturation declines. These characteristics result in (a) the pick up of oxygen by haemoglobin being maintained despite reduced oxygen tension, and (b) delivery of oxygen to the tissues being maintained despite progressively falling oxyhaemoglobin saturation. Figure reproduced with permission from Beasley et al.' tension. Regardless, the impaired oxygen delivery at the tissue level results in depressed cellular respiration and potential organ dysfunction.

These adverse effects are not widely known and high flow oxygen is widely prescribed to breathless patients, regardless of the presence of arterial hypoxaemia. Even in patients with exacerbations of chronic obstructive pulmonary disease in respiratory failure, the risks of high flow oxygen therapy are often not recognised. ${ }^{20}$

Perhaps the least recognised risk with high flow oxygen is that its use may lead to a delay in the ability to recognise and treat a progressive deterioration in pulmonary function. ${ }^{621}$ This risk has been well quantified by Downs and colleagues through modelling of the effects of different oxygen regimes in the situation of a progressively increasing intrapulmonary shunt (fig 2). ${ }^{21}$ In this clinical scenario, the use of high flow oxygen can delay the recognition of a deterioration in respiratory function as there is likely to be no major change in vital signs ${ }^{22}$ and minimal decrease in oxygen saturation assessed by pulse oximetry ${ }^{23}$ until a life threatening situation has developed. This may provide a false reassurance that the patient is stable. At this stage there is limited opportunity to further increase the oxygen therapy while medical review and an intervention such as transfer to the intensive care unit (ICU) is undertaken. In contrast, if low flow oxygen therapy is initially used to achieve oxygen saturations around 95\%, a subsequent clinical deterioration is likely to be recognised sooner through pulse oximetry, and there is the option of increasing the oxygen therapy while medical review and the required intervention is undertaken (see case example and fig 2).

Thus, inappropriately high flow oxygen has the potential to cause both a delay in recognising clinical deterioration and a reduction in the time available to institute additional treatment. This is contrary to the common assumption that administration of high flow oxygen in a breathless patient will have a protective effect in the event that pulmonary function deteriorates.

In accepting that there are significant risks with high flow oxygen, what is the alternative to the current practice of immediate placement of high flow oxygen in the breathless patient regardless of the presence of arterial hypoxaemia? We recommend that, as part of the initial assessment of an acutely breathless patient, oxygen saturation is measured by oximetry. If the oxygen saturation is $>92 \%$, oxygen therapy need not be routinely administered. If the oxygen saturation is $85-92 \%$, oxygen therapy could be initially instituted at 2-3 litres via nasal cannula which would 


\section{Case example*}

A 30-year-old patient with community acquired pneumonia presents with a CURB-65 severity score of 1 , with no confusion, urea $6.5 \mathrm{mmol} / \mathrm{l}$, respiratory rate $35 / \mathrm{min}$ and blood pressure $115 / 65$. $\mathrm{He}$ is admitted because of the associated clinical features of an oxygen saturation of $88 \%\left(\mathrm{PaO}_{2} 58 \mathrm{~mm} \mathrm{Hg}\right)$ and bilateral changes on his chest radiograph. $\mathrm{He}$ is admitted to the ward, treated with intravenous antibiotics, and monitored with continuous pulse oximetry and clinical recordings. His pneumonia worsens, with right to left intrapulmonary shunting of blood increasing by $1 \%$ every $6 \mathrm{~min}$.

(a) With an $\mathrm{FiO}_{2}$ of 0.3 (2-3 litres via nasal cannula), the saturation initially increases to $95 \%$ but then, with the progressive deterioration, decreases to a saturation of $<90 \%$ in about $60 \mathrm{~min}$. At this stage the oxygen therapy can be increased to an $\mathrm{FiO}_{2}$ of 0.6 , with a saturation increasing to and remaining $>90 \%$ despite further deterioration during the 30-60 min required to arrange medical review and transfer to the ICU.

(b) An $\mathrm{FiO}_{2}$ of 0.6 (8-10 litres via Hudson mask) would initially increase the saturation to around $100 \%$ but, with the same rate of deterioration, the decrease to a saturation of $<90 \%$ would take about $2 \mathrm{~h}$. During this period it is unlikely that the deterioration would be recognised clinically through monitoring of clinical signs ${ }^{22}$ or pulse oximetry. Once the saturation has fallen to $<90 \%$, there is limited opportunity to further increase the inspired oxygen and the saturations would decrease further during medical review and ICU transfer.

*This case example was derived from Downs and Smith. ${ }^{21}$ The rate of increase in right to left shunting was $2 \%$ per minute in the original reference compared with $2 \%$ per $12 \mathrm{~min}$ in this case example to ensure a more clinically relevant deterioration.

be expected to increase the saturation above $92 \%$. An oxygen saturation of $<85 \%$ is likely to require higher flows through a simple mask, titrated to achieve a saturation above $92 \%$. Importantly, in the situation of arterial hypoxaemia, the priorities are to identify the cause and severity of the underlying disorder and to administer the required specific treatment in addition to titrated oxygen therapy.

We suggest that, in clinical teaching, the risks of high flow oxygen are presented with discussion of both the adverse physiological effects and potential for
Intrapulmonary shunt (\%)

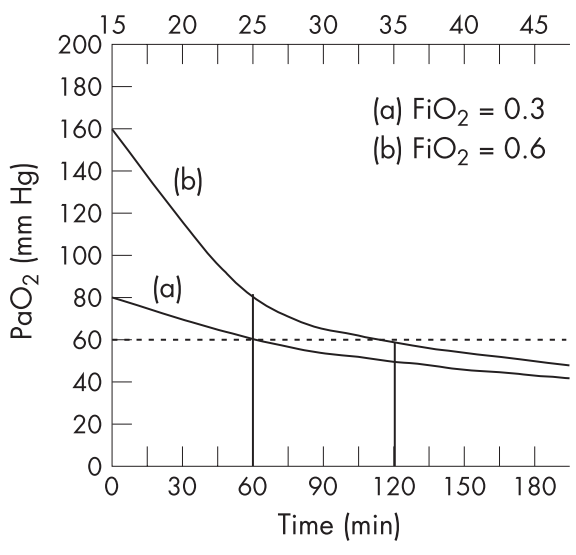

Figure 2 Arterial oxygen tension $\left(\mathrm{PaO}_{2}\right)$ plotted as a function of intrapulmonary shunt increasing at a rate of $1 \%$ per 6 min with fractional inspired oxygen ( $\mathrm{FiO}_{2}$ ) of (a) 0.3 and (b) 0.6 . In example (a) with $\mathrm{FiO}_{2} 0.3$, the time required for the $\mathrm{PaO}_{2}$ to decrease from $80 \mathrm{~mm} \mathrm{Hg}$ (95\% saturation) to $<60 \mathrm{~mm} \mathrm{Hg}$ (<90\% saturation) is around $60 \mathrm{~min}$. At this stage, with the same rate of increasing intrapulmonary shunt, an increase in $\mathrm{FiO}_{2}$ from 0.3 to 0.6 will maintain the $\mathrm{PaO}_{2}$ above $60 \mathrm{~mm} \mathrm{Hg}$ for about a further $60 \mathrm{~min}$. In example (b), if the patient receives an $\mathrm{FiO}_{2}$ of 0.6 , it would take around 120 min for the $\mathrm{PaO}_{2}$ to decrease to $<60 \mathrm{~mm} \mathrm{Hg}$ (<90\% saturation). At this stage, with the same rate of increasing intrapulmonary shunt, there will be a further deterioration in $\mathrm{PaO}_{2}$ despite maintenance of the $\mathrm{FiO}_{2}$ at 0.6 . Reproduced with modification from Downs and Smith. ${ }^{21}$

delay in the recognition of a deteriorating clinical condition. This would reinforce the awareness that oxygen is a drug that should be prescribed for defined indications in which the benefits outweigh the risks, and that prescriptions should specify the dose, method and duration of delivery and the patient's response to oxygen therapy should be monitored. ${ }^{24}$

Thorax 2007;62:840-841.

doi: $10.1136 /$ thx.2006.068866

\section{Authors' affiliations}

Richard Beasley, Medical Research Institute of New Zealand, Wellington, New Zealand and University of Southampton, Southampton, UK Sarah Aldington, Geoffrey Robinson, Medical Research Institute of New Zealand, Wellington, New Zealand

Correspondence to: Professor Richard Beasley, Medical Research Institute of New Zealand, P'O Box 10055, Wellington, New Zealand; Richard. Beasley@mrinz.ac.nz

Competing interests: None.

\section{REFERENCES}

I Beasley R, McNaughton A, Robinson GM. New look at the oxyhaemoglobin dissociation curve. Lancet 2006;367:1124-6.
2 Albin RJ, Criner GJ, Thomas S, et al. Pattern of non-ICU inpatient supplemental oxygen utilization in a university hospital. Chest 1992;102:1672-5.

3 Kor AC, Lim TK. Audit of oxygen therapy in acute general medical wards following an educational programme. Ann Acad Med Singapore 2000;29:177-81.

4 Denniston AKO, Stableforth DE, O'Brien C. The use of oxygen in acute exacerbations of chronic obstructive pulmonary disease: a prospective audit of pre-hospital and hospital emergency management. Clin Med 2002;2:449-51.

5 Thomson AJ, Webb DJ, Maxwell SRJ, et al. Oxygen therapy in acute medical care: the potential dangers of hyperoxia need to be recognised. BMJ 2002;324: 1406-7.

6 Downs JB. Has oxygen administration delayed appropriate respiratory care? Fallacies regarding oxygen therapy. Respir Care 2003;48:61 1-20.

7 Wagner PD, Laravuso RB, Uhl RR, et al. Continuous distributions of ventilation-perfusion ratios in normal subjects breathing air and 100 per cent oxygen. $J$ Clin Invest 1974;54:54-68.

8 Markello R, Winter P, Olszowka A. Assessment of ventilation-perfusion inequalities by arterialalveolar nitrogen differences in intensive care patients. Anesthesiology 1972;37:4-15.

9 Caldwell PRB, Lee WL Jr, Schildkraut HS, et al. Changes in lung volume, diffusing capacity, and blood gases in men breathing oxygen. J Appl Physiol 1966;21:1477-83.

10 Eggers GWN, Pakey HW, Leonard J, et al. Haemodynamic responses to oxygen breathing in man. J Appl Physiol 1962;17:75-9.

11 Daly WJ, Bondurant S. Effects of oxygen breathing on heart rate, blood pressure and cardiac index of normal resting man, with reactive hyperemia and after atropine. J Clin Invest 1962;41:126-32

12 Bourassa MG, Campeau L, Bois MA, et al. The effects of inhalation of 100 per cent oxygen on myocardial lactate metabolism in coronary heart disease. Am J Cardiol 1969;24:172-7.

13 Kety SS, Schmidt CF. The effects of altered arterial tensions of carbon dioxide and oxygen on cerebral blood flow and cerebral oxygen consumption of normal young men. J Clin Invest 1948;27:484-92.

14 Aber GM, Harris AM, Bishop JM. The effect of acute changes in inspired oxygen concentration on cardiac, respiratory and renal function in patients with chronic obstructive airways disease. Clin Sci 1964;26:133-43.

15 Rawles JM, Kenmure AC. Controlled trial of oxygen in uncomplicated myocardial infarction. BMJ 1976;1:1121-3.

16 Ronning OM, Guldvog B. Should stroke victims routinely receive supplemental oxygen? A quasirandomized controlled trial. Stroke 1999;30:2033-7.

17 Davis PG, Tan A, O'Donnell CPF, et al. Resuscitation of newborn infants with $100 \%$ oxygen or air: a systematic review and meta-analysis. Lancet 2004;364:1329-33

18 Garner WL, Downs JB, Reilley TE, et al. The effects of hyperoxia during fulminant sepsis. Surgery 1989;105:747-51

19 Reinhart K, Bloos F, König F, et al. Reversible decrease of oxygen consumption by hyperoxia. Chest 1991;99:690-4.

20 Plant PK, Owen JL, Elliott MW. One year period prevalence study of respiratory acidosis in acute exacerbations of COPD: implications for the provision of non-invasive ventilation and oxygen administration. Thorax 2000;55:550-4.

21 Downs JB, Smith RA. Increased inspired oxygen concentration may delay diagnosis and treatment of significant deterioration in pulmonary function. Crit Care Med 1999;27:2844-6.

22 Thrush DN, Downs JB, Hodges $M$, et al. Does significant arterial hypoxemia alter vital signs? J Clin Anesth 1997:9:355-7.

23 Fu ES, Downs JB, Schweiger JW, et al. Supplemental oxygen impairs detection of hypoventilation by pulse oximetry. Chest 2004;126:1552-8.

24 Dodd ME, Kellet F, Davis A, et al. Audit of oxygen prescribing before and after the introduction of a prescription chart. BMJ 2000;321:864-5. 